\title{
Structure Health Monitoring Method based on Electrio-Mechanical Impedance (EMI) Technique
}

\author{
Ma Feng ${ }^{1}$, Qin Lei ${ }^{2, a, ~ *}$, Xiaochang $\mathrm{Ni}^{1}$, Xiaojun Zhu ${ }^{1}$, Shifeng Huang ${ }^{2}$ \\ ${ }^{1}$ School of Civil Engineering ang Architecture, University of Jinan, Jinan250022, China \\ ${ }^{2}$ School of Material Engineering, University of Jinan, Jinan 250022, China \\ acea_qinl@ujn.edu.cn
}

Keywords: EMI, Nondestructive monitoring

\begin{abstract}
PZT sensor was placed in different position which damaged in order to determine the feasibility of EMI technology to the detection for damage of the concrete structure, and 4294A Agilent precision impedance tester used in different frequency of concrete specimens under different damage conditions of the EMI signal measurement. After several experiments, and find out the frequency of the peak value of the EMI signal. And the different damage degree and the peak value of the signal are tested in the frequency of the peak value of the EMI signal. There is a certain correlation between the degree and location of damage and the peak value of the spectrum, the feasibility of the EMI technique for the monitoring for the damage degree of specimen is determined.
\end{abstract}

\section{Introduction}

Piezoelectric materials have been widely used in the health monitoring of concrete structures due to their excellent properties. The piezoelectric materials cannot only be used as a driver but also can be used as a sensor in the health monitoring for the health monitoring of concrete structure. EMI technique has shown potential application prospect in the fields of civil engineering. In 1999-2001, Park et al. has applied this technology by affixing PZT sensors to the reinforced brickwork, joint part of steel structure bridge and pipe network to detect the EMI variation of the concrete structures [1-3]. In 2000, Soh et al. Studied the application feasibility of the EMI technology on health monitoring of steel concrete bridge [4]. By affixing PZT sensor to critical section of the bridge. In 2002, Bhalla et al. and Naidu et al. monitored the initial damage of concrete structure by using the EMI technique, and meanwhile they have also monitored the strength increase of concrete during curing by using the EMI technique and obtained the correlation between concrete stiffness and the peaks value of the EMI signal [5-7]. In 2002-2005, Giurgiutiu et al. performed the structural online health monitoring in conjunction with the EMI technique and Lamb wave sensor into the structure. Furthermore, they also presented an approach to damage metric quantification based on the comparison and classification of high-frequency local impedance spectra [8-10]. In 2010, Tawie and Lee validate the EMI technique in monitoring the strength development in concrete, and their research results showed that the relative strength gain of concrete can be predicted by monitoring the EMI spectrum curve shift [11]. In this paper, the drilling of cubic concrete specimen was simulated by drilling rig with different degrees of damage. The piezoelectric sensor is pasted on the surface of the concrete structure, and measure EMI signals by PZT sensor. The test results are analyzed and compared, and find out the relationship between structural damage and admittance spectrum curve.

\section{Experimental Investigation}

In this paper, the damage of structural members is monitored by piezoelectric impedance method. The performance of piezoelectric ceramics as well as the monitoring of the excitation voltage and other factors, due to the limitations of piezoelectric. The influence of the distance of the distance member on the monitoring result is considered. The purpose of this experiment is on the basis of the research, the influence of different distance of the piezoelectric ceramic sensor on the monitoring results is studied. 


\subsection{Experimental}

The size of the size of concrete beam is $150 \mathrm{mmX} 150 \mathrm{mmX} 500 \mathrm{~mm}$. The Concrete mix proportion was Cement: water: sand: Gravel=1:0.45:1.95:3.20. The experiment was carried out after 28 days of age. The piezoelectric ceramic sheets are used in series of PZT-4. Then, when the specimens reaches target strength, then drilling a hole in the distance at the end of $100 \mathrm{~mm}$, damage simulation of concrete beams, and the depth of the hole is $50 \mathrm{~mm}$, diameter is $12 \mathrm{~mm}$. Finally, affixing the PZT sensors to the damaged concrete beam, the distance from the damage to the PZT sensors were $100 \mathrm{~mm}, 200 \mathrm{~mm}$, 300mm are marked as S1, S2, S3, the position of damage and PZT as shown in Figure 2.1.

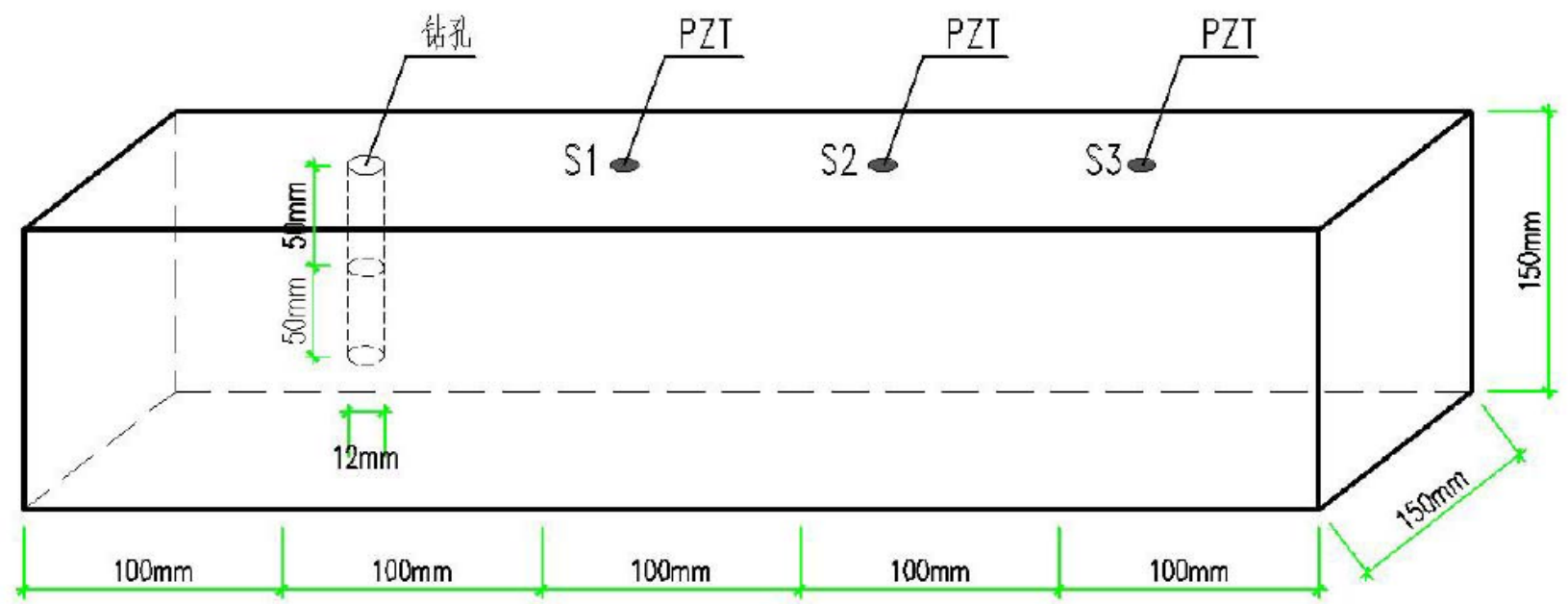

Fig. 2.1 Damage location and arrangement of piezoelectric ceramic

\subsection{Test results and analysis}

The 4294A Agilent precision impedance tester was used to test the range of different frequency band, and the admittance spectrum curve of each piezoelectric ceramic chip under different damage degree. The test process is shown in Figure 2.2.

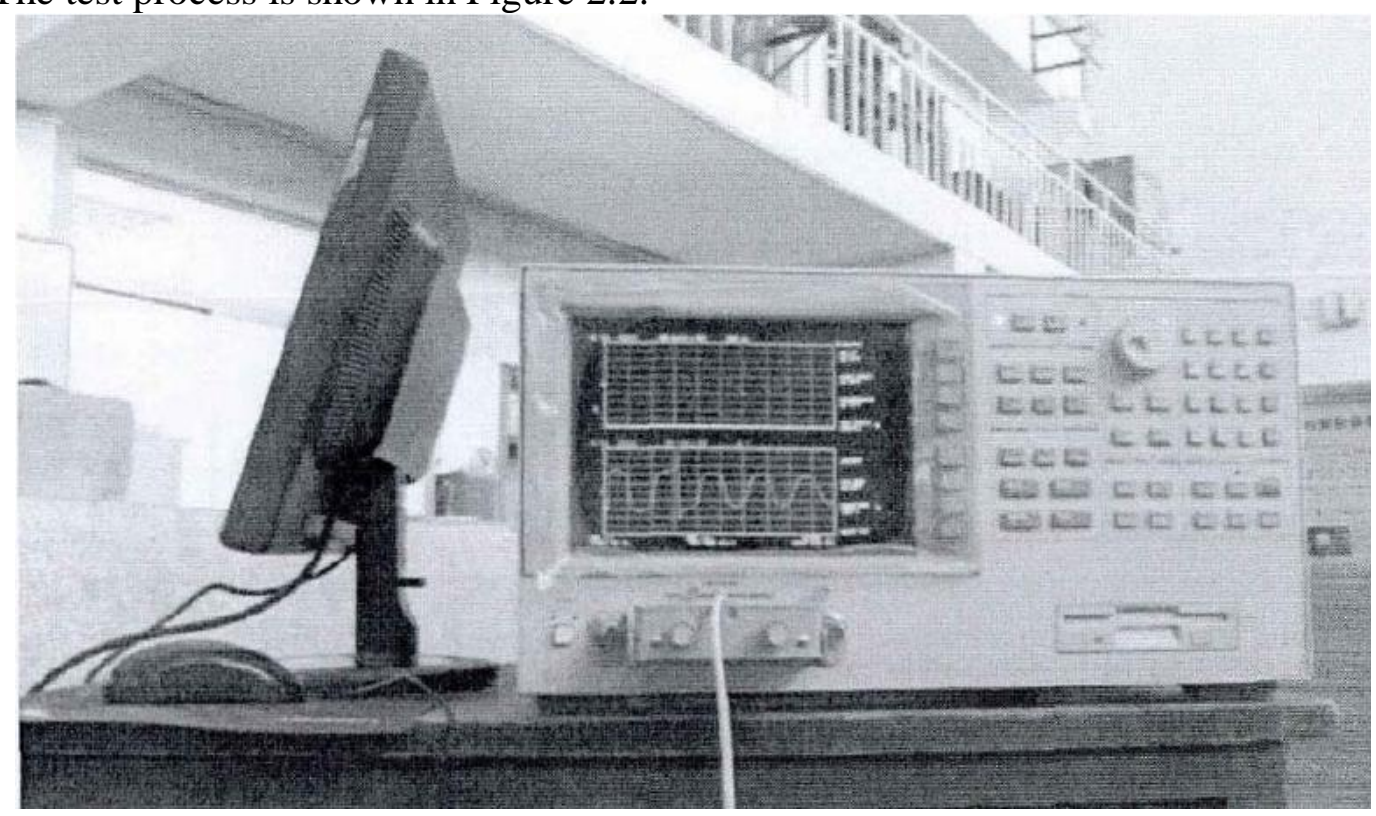

Fig. 2.2 4294A Agilent precision impedance tester

First, $40 \mathrm{~Hz}-4 \mathrm{MHz}$ test in the whole frequency range under different injury conditions of the spectrum, the test results are shown in Figure 2.3, we can see in different damage cases, the spectrum

curve changes significantly and is still in the band $100-300 \mathrm{kHz}$ and $1-3 \mathrm{MHz}$ frequency range, which is PZT sensors in this band is more sensitive to the injury in this test. Therefore, still in the two band, the test results as shown in Figure 2.4 and figure 2. 

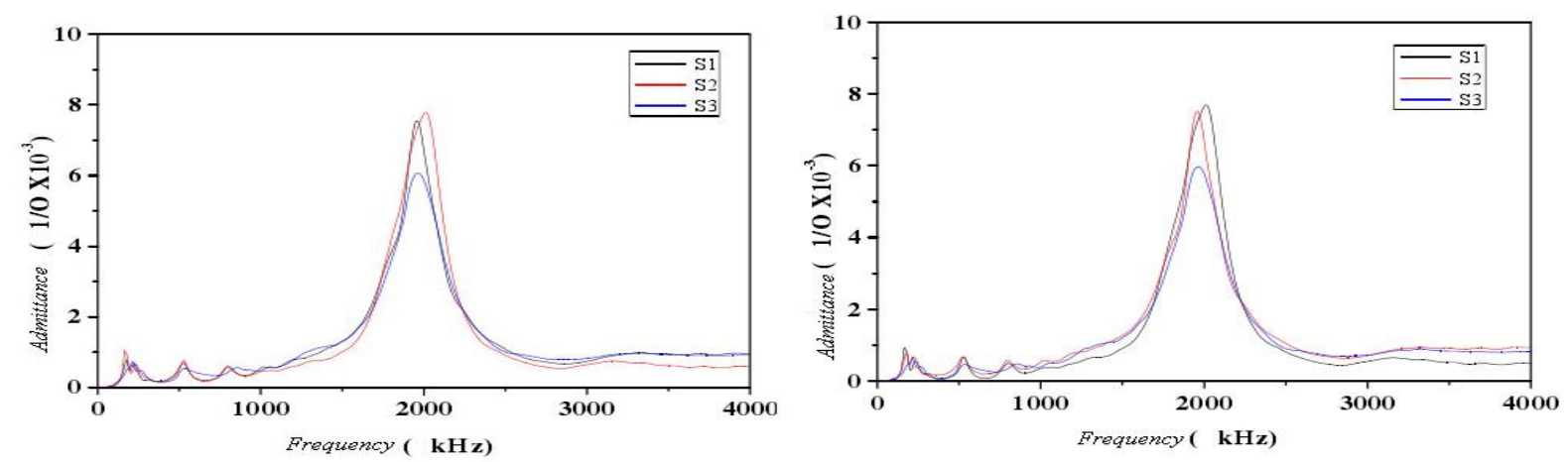

a) Admittance diagram of PZT under 50mm damage b) Admittance diagram of PZT under 100mm damage Figure 2.3 PZT under different damage degree
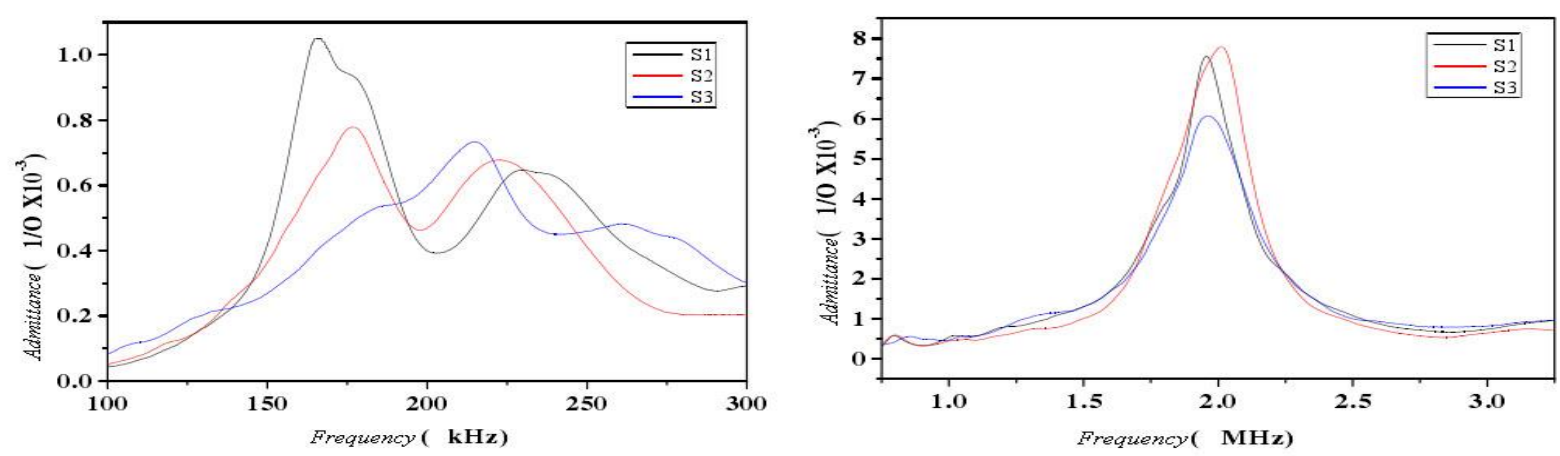

a)PZT admittance diagram at $100-300 \mathrm{kHz}$ frequency b) PZT admittance diagram at $1-3 \mathrm{MHz}$ frequency Figure 2.4 PZT in the case of 50mm damage
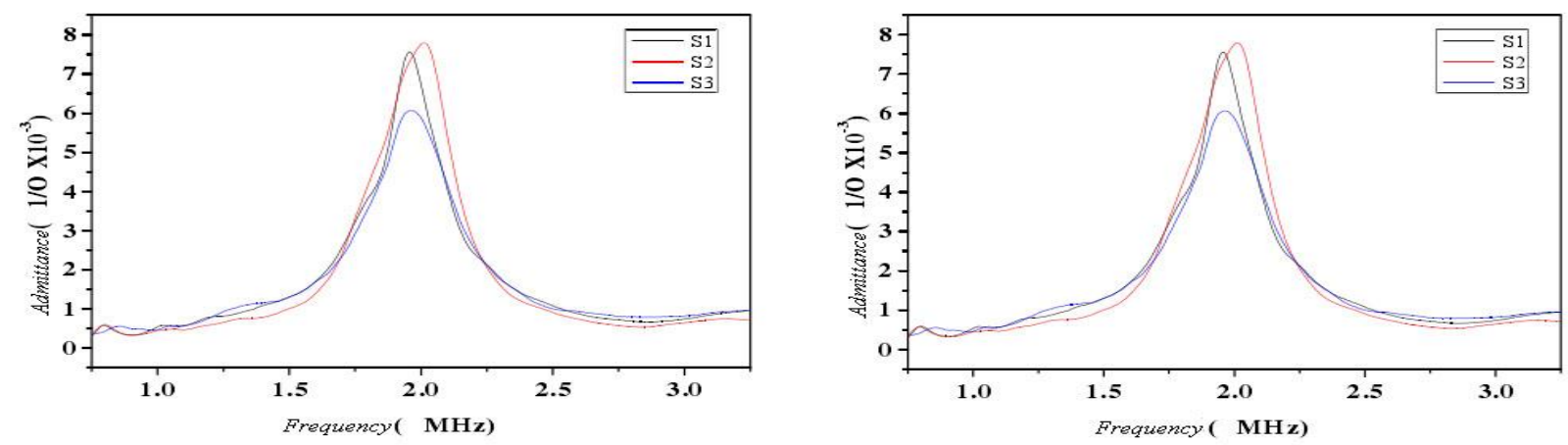

a)PZT admittance diagram at $100-300 \mathrm{kHz}$ frequency b) PZT admittance diagram at $1-3 \mathrm{MHz}$ frequency Figure 2.5 PZT in the case of $100 \mathrm{~mm}$ damage

It can be seen in figure 2.4 and figure 2.5 that the piezoelectric ceramic sheet S2 is a patch which is damaged by the distance component $100 \mathrm{~mm}$. The spectrum peak is the largest, and the third piezoelectric ceramic pieces are the distance component damage $150 \mathrm{~mm}$, which is the most remote patch. In order to make the monitoring result more reliable and scientific, in the future, we can consider the Size to do more, in the beam of the different position of the sensor, in order to determine the location in which the distance to the damage. A lot of tests are needed to verify that the location of the location can be monitored to get more accurate results.

\section{Conclusion and Prospect}

In this paper, the EMI technique is used to detect the damage of concrete beam. In experiment, the influence of PZT sensors on the detection results of different distance of concrete damage is studied. The detection results of different sensors and different damage degree are shown: the distance between the piezoelectric sensor and the concrete beam has a great influence on the test results. The closer the PZT sensor is, the more obvious the detection results are, on the contrary, the farther the piezoelectric 
sensor is, the less the detection results are. The occurrence of damage in the concrete structure will lead to the migration of the EMI spectrum curve, and the peak value of the curve will decrease. At the same time, the damage degree of concrete structure increases. The peak value of the curve decreases and the trend of offset increases.

\section{Acknowledgements}

The financial support is from the National Natural Science Foundation of China (51378239).

\section{References}

[1] Park G, Cudney HH, Inman DJ. Impedance-based health monitoring technique for massive structures and high-temperature structures. Proc SPIE 1999; 3670: 461-9.

[2] Park G, Cudney HH, Inman DJ. Impedance-based health monitoring of civil structural components. J Infrastruct Syst ASCE 2000; 6:153-60.

[3] Park G, Cudney HH, Inman DJ. Feasibility of using impedance-based damage assessment for pipeline systems. Earthq Eng Struct Dyn 2001; 30: 1463-74.

[4] Soh CK, Tseng KKH, Bhalla S, Gupta A. Performance of smart piezoceramic patches in health monitoring of a RC bridge. Smart Mater Struct 2000; 9: 533-42.

[5] Bhalla S, Naidu ASK, Ong CW, Soh CK. Practical issues in the implementation of electromechanical impedance technique for NDE. In: Proc SPIE 2002, SPIE's international symposium on smart materials, nano-, and micro-smart systems, Australia, Melbourne; 2002.

[6] Naidu A, Bhalla S. Damage detection in concrete structures with smart piezoceramic transducers. In Proc ISSS-SPIE 2002, int conf smart mater struct syst, India, Bangalore; 2002.

[7] Naidu A, Bhalla S, Soh CK. Incipient damage localization with smart piezoelectric transducers using high-frequency actuation. In: Proc SPIE 2002, SPIE's int symp on smart mater nano-, and micro-smart syst, Australia, Melbourne; 2002.

[8] Giurgiutiu V, Zagrai AN. Embedded self-sensing piezoelectric active sensors for online structural identification. ASME J Vib Acoust 2002; 124: 116-25.

[9] Giurgiutiu V, Bao J. Embedded ultrasonic structural radar for the nondestructive evaluation of thin-wall structures. In: Proc IMECE 2002, ASME int mecha eng cong, New Orleans, LA; 2002.

[10] Giurgiutiu V, Adrian C. Embedded non-destructive evaluation for structural health monitoring, damage detection, and failure prevention. The Shock. Vib Digest 2005; 37: 83-105.

[11] Tawie R, Lee HK. Monitoring the strength development in concrete by EMI sensing technique. Constr Build Mater 2010; 24: 1746-53. 